\title{
Extramural Research Grants and Scientists' Funding Strategies Beggars Cannot be Choosers?
}

\author{
Grimpe, Christoph
}

\author{
Document Version \\ Accepted author manuscript \\ Published in: \\ Research Policy \\ DOI: \\ 10.1016/j.respol.2012.03.004 \\ Publication date: \\ 2012

\section{License \\ CC BY-NC-ND}

Citation for published version (APA):

Grimpe, C. (2012). Extramural Research Grants and Scientists' Funding Strategies: Beggars Cannot be Choosers? Research Policy, 41(8), 1448-1460. https://doi.org/10.1016/j.respol.2012.03.004

Link to publication in CBS Research Portal

\section{General rights}

Copyright and moral rights for the publications made accessible in the public portal are retained by the authors and/or other copyright owners and it is a condition of accessing publications that users recognise and abide by the legal requirements associated with these rights.

Take down policy

If you believe that this document breaches copyright please contact us (research.lib@cbs.dk) providing details, and we will remove access to the work immediately and investigate your claim. 


\section{Extramural Research Grants and Scientists' Funding Strategies: Beggars Cannot be Choosers?}

\section{Christoph Grimpe}

Journal article (Post print version)

This article was originally published in Research Policy, Vol. 41, Issue 8, Pages 14481460. First published online April 3, २०12.

DOI: 10.1016/j.respol.2012.03.004

(2) 2016. This manuscript version is made available under the CC-BY-NC-ND 4.0 license http://creativecommons.org/licenses/by-nc-nd/4.0/ 


\title{
Extramural Research Grants and Scientists’ Funding Strategies: Beggars Cannot Be Choosers?
}

\author{
Christoph Grimpe \\ Copenhagen Business School \\ Dept. of Innovation and Organizational Economics \\ Kilevej 14A, 2000 Frederiksberg, Denmark \\ Phone: +45 3815 2530, e-mail: cg.ino@cbs.dk
}

Published in Research Policy, Vol. 41, 1448-1460. The final version can be found at http://www.sciencedirect.com/science/article/pii/S0048733312000649

\begin{abstract}
Although competitive funding of public research has been characterised as providing output incentives that raise efficiency and productivity, we know very little about whether the quality of a scientist's research is in fact the primary award criterion on which funding bodies base their grant decision. This paper provides insights into scientists' strategies for obtaining project-based research funding in the presence of multiple funding opportunities. It draws a distinction between four types of grants, including the Sixth Framework Programme for Research and Technological Development (FP6), government, foundation, and industry grants. Based on a sample of more than 800 scientists at universities and public research institutes in Germany, the results indicate that scientist productivity measured in terms of publication and patent stock is a statistically significant determinant only for obtaining foundation and industry grants while the award of an FP6 or government grant are influenced by other characteristics. The results further show that the different grants are not complementary, i.e. scientists specialise in certain grants. In this respect, the analysis informs science, technology and innovation policy about potential discrepancies between policy rhetoric, stipulated award criteria, and actual funding outcomes which makes it possible to fine-tune the debate on how public research should be financed.
\end{abstract}

Keywords: Research funding, scientist productivity, Sixth Framework Programme JEL classification: L13, O31 


\section{$1 \quad$ Introduction}

In many European countries, public research has traditionally been funded through a mix of institutional ("lump sum”) funding and project-based, extramural research grants (Schmoch and Schubert, 2009). To raise these grants, scientists at universities and public research organisations (PROs) can target a variety of funding sources, including the government, research foundations, and industry. Moreover, since the 1980s, the European Union (EU) has developed its own science, technology and innovation (STI) policy independent of the member states, which led to the creation of the Framework Programme for Research and Technological Development (FP) (Marin and Siotis, 2008). In recent years, the share of research grants has increased significantly compared to institutional funding (Auranen and Nieminen, 2010). The policy rationale for this development is the idea that competitive funding of public research provides output incentives, which raises efficiency and productivity compared to traditional funding mechanisms (Bolli and Somogyi, 2011). According to aggregate data from the OECD, industry sources, for example, are financing a growing share of academic research while "core" public funding is going down. ${ }^{1}$

While this ongoing shift from fixed to more variable research funding increases competition for extramural grants, it implies that scientists need to develop funding strategies to be successful. Like all economic agents, scientists can be assumed to select those grants for which they anticipate the highest "return". In this respect, return refers to the balance between the effort involved in walking through the application process, in managing the project and coping with the administrative burden (if funding is received), and the amount of the funding itself, weighted by the probability of receiving the grant. As virtually all funding bodies claim to apply competitive, merit-based selection procedures, common sense would suggest that the probability of receiving the grant is dependent on the scientist's research productivity and quality.

Apart from anecdotal evidence, however, we know very little about whether the quality of a scientist's research is in fact the primary award criterion on which funding bodies base their grant decision. Research quality is also reflected in different output indicators, most prominently publications and patents, which might not be equally conducive to being awarded a particular grant. Moreover, prior literature is rather silent on the role that not only research characteristics but also personal, institutional and disciplinary factors play in obtaining external funding. While such funding itself might be tough to attain, scientists in many European countries are typically confronted with a bewildering variety of grants and funding instruments. Based on the assumption that scientists make rational choices for a particular grant, this paper intends to provide insights into scientists' funding strategies in the presence of multiple funding opportunities. It draws a distinction between four major types of grants: the FP at the European level, the national government, research foundations, and industry. Furthermore, the analysis not only sheds light on the choice but also on the actual scale to

Although the share of industry grants is still rather small, data from the OECD's Main Science and Technology Indicators show that it has been growing since 1980. (OECD, 2010). 
which the four types of grants contribute to the scientist's total research budget. The context chosen for this study is Germany, which is characterised by a well-developed funding infrastructure. Moreover, the overall share of project-based funding of public science in Germany has increased substantially from 14 per cent in 1995 to 18 per cent in 2000 (DFG, 2009a), indicating a high relevance for scientists to acquire grants. The results not only enlighten our understanding of the determinants of funding outcomes but they also show - for the German context - whether scientists tend to focus on a particular type of grant or whether they choose to build their research budget from several sources. In this respect, the paper shows which grants are complementary and which of them could be considered as substitutes.

Investigating the funding strategies of scientists in public research is important for at least two reasons. First, uncovering the "true" award criteria of different types of grants makes it possible to fine-tune the debate on how competitive research funding can stimulate efficiency and productivity of the public research system. In this respect, the analysis informs STI policy on potential discrepancies between policy rhetoric, stipulated award criteria, and actual funding outcomes. Second, the analysis provides useful information for the scientists themselves regarding which type of grant promises the highest success chances, given a particular combination of research, personal, institutional, and disciplinary characteristics.

The remainder of the paper is organised as follows: Section 2 provides a review of the policy rationale and context for research funding and sheds light on the different types of grants and their characteristics. Section 3 elucidates the role research as well as other characteristics play for the choice of a particular type of grant. Section 4 describes the sample of German scientists at universities and PROs as well as the methods chosen while the results are presented in section 5 . The paper concludes in section 6 with a discussion of the results as well as implications for STI policy and further research opportunities.

\section{Background}

\subsection{Policy rationale}

The major STI policy objective for allocating research funds on a competitive basis is to increase efficiency and productivity in public science (e.g. Bolli and Somogyi, 2011). Although the relationship between financial incentives and the efficiency of university systems is not unambiguous (Auranen and Nieminen, 2010), there is ample empirical evidence suggesting that the competitive allocation of grants actually has an impact on scientist behaviour and activities.

In this respect, research grants are found to increase individual productivity (Stephan, 1996; Lee and Bozeman, 2005) although this relationship is moderated by the scientist's career stage (Arora and Gambardella, 2006) and the size of the grant (Godin, 2003). Moreover, most research grants are intended to stimulate collaborative behaviour among scientists (Defazio et al., 2009). While funding oriented towards teams of scientists has been shown to increase collaborative behaviour (Arora et al., 1998; Adams, 2005), the effect of collaboration on 
research productivity is less clear. Arora et al. (1998) find that, despite a negative effect of funding on team productivity, scientists would not have collaborated without funding. Lee and Bozeman (2005) show that funding is positively linked with collaboration and productivity even though they do not investigate the effect of funded collaboration on productivity. Evaluating these inconclusive results, Defazio et al. (2009) argue that funding cannot necessarily be regarded as productivity enhancing although it may enable scientists to further existing collaboration in ways that would otherwise be more difficult to achieve. Based on a panel of 294 scientists in collaborative projects financed through the FP, they distinguish between pre-, during- and post-funding periods and show that collaborations specifically formed to benefit from funding opportunities do not stimulate productivity in the short run but serve as effective instruments to enhance productivity in the longer run.

Although extramural research grants are hence not necessarily a universal tonic for increasing efficiency and productivity in public science, many countries have developed a diversified research funding infrastructure. Taking into account that research projects have also increasingly been commissioned by the private sector, scientists are confronted with a bewildering variety of funding opportunities. Adopting a parsimonious classification of research grants that groups similar grants together, four distinct categories of funding sources can be identified. These include the FP on the European level, the national government, research foundations, and industry. In the following, this paper focuses on the funding context for scientists in Germany. This setting is particularly interesting since Germany took the lion's share of funding in the latest FP and at the same time features a highly developed research funding infrastructure (BMBF, 2009).

\subsection{The German funding context}

Starting at the supra-national level, the Framework Programmes are funding programmes created by the EU to support and encourage research in the European Research Area (ERA). They are organised in funding periods with specific objectives and actions. The most recently completed FP is the Sixth Framework Programme (FP6). With a budget of almost 17 billion Euro, FP6 provided funding for R\&D projects in the years 2002 to 2006. The FPs typically award grants for technology-oriented research joint ventures that comprise partners from various countries (Marin and Siotis, 2008). FP funding is awarded subject to several conditions that the prospective consortia must meet. First, the projects need to be precompetitive to prevent conflicts with EU competition law. At the same time, however, they are expected to strengthen the competitiveness of EU firms, either through having them participate directly in projects or through deliberate knowledge and technology transfer and broad dissemination of the project outcomes. They should also demonstrate their usefulness for policy making. Second, in order to increase the chance of funding, consortia need to exhibit a fair representation of partners from "peripheral" countries, including for example the new member states from Central and Eastern Europe (Marin and Siotis, 2008). A major drawback of participation in the FPs from the scientists' perspective has been the substantial administrative burden associated with the application for and management of projects, which has frequently been described as very costly and time consuming (Luukkonen, 2002). Moreover, scientists have criticised the requirement to form unsuitably large consortia, 
particularly for the social sciences and humanities, as well as a rather narrow definition of research topics (BMBF, 2009).

Like its predecessors, the FP6 did not cover all areas of science and technology but instead focused on a limited number of thematic priorities in which projects were carried out. Nevertheless, the FP's scope has become broader over time, meanwhile covering a wide range of themes and funding instruments that also include the mobility of researchers (European Commission, 2002). Similarly, the economic and political justification for the FPs has become more elaborate. While the FPs up to the FP4 declared added value through networking, cohesion and scale benefits to be a sufficient justification, the FP5 shifted the focus towards socio-economic benefits in general. The launch of the FP6 corresponded to the implementation of the European Research Area, which aims at bundling resources for research to create a system of scientific excellence that could readily compete with those of the U.S. and Japan. In order to build scale, the FP6 therefore featured larger funding instruments with the objective of bringing together the scientific elite from various countries (Marin and Siotis, 2008). In fact, in recent years, the FPs have become a widely used instrument (Rietschel, 2009).

The second type of research grant analysed in this paper is the so-called R\&D project support of the federal government, provided through thematic R\&D programmes. Although the government offers several other institutional as well as project-based funding instruments, the R\&D project funding is the most significant (BMBF, 2008). Grants can be sought in those fields of research and technology that have been pre-defined by the different ministries. Hence, this type of project funding directs the research activities in a certain direction. The objective of the funding programmes is to facilitate a high level of research performance in selected fields. An example of this is the so-called high-tech strategy of the federal government (DFG, 2009a). Launched in 2006 and endowed with a budget of 14.6 billion Euro for the period from 2006 to 2009, this strategy aims at creating favourable conditions for economic growth and job security in Germany. Areas targeted for the R\&D project grants are health, climate and environmental protection, mobility and safety, as well as the development of future key technologies like bio- and nanotechnology. Besides these areas, R\&D project funding can however also be sought in the social sciences and humanities.

About one third of the $R \& D$ project funding is awarded to the private sector while universities and PROs share the remaining part (DFG, 2009a). Public science participates in the project grants to a varying degree, depending on the field of research. In the health research area, for example, universities benefit particularly from the funding of large research infrastructure. In contrast to this, universities benefit relatively less in engineering oriented fields of research.

The third type of research grant analysed here comprises grants sponsored by research and science foundations. The most important funding body in this category is the German Research Foundation (DFG), the main sponsor of academic research in Germany and the largest research support organisation in Europe (DFG, 2009a). Projects sponsored are usually not application oriented but instead basic research. The foundation is organised as a selfgoverning body, and the decision committees consist of members from universities and PROs. 
It provides funding to all areas of research. Grants are awarded on the basis of a competitive procedure in which applications are peer reviewed. The reviews themselves are subject to evaluation in order to make sure that the same quality criteria are applied to all grant applications. For the period from 2005 to 2007, the foundation made grant decisions totalling 5.8 billion Euro. One of the highest endowed grants is the "Leibniz Prize", which is awarded annually to ten distinguished scientists who receive "honour, prize money and idyllic freedom” (DFG, 2009b). Due to the highly competitive selection procedure, grants awarded by the foundation convey a high reputation.

Besides the German Research Foundation there are other foundations like the Volkswagen Foundation that enjoy a high reputation equal to that of the German Research Foundation. While those foundations are typically endowed by private sponsors, the German Research Foundation receives its budget from the German federal and state governments. Although this could be considered government funding, the two sources - government and foundations can be regarded as distinct because the award decisions are made by different bodies. Moreover, due to the governance model of the German Research Foundation, the government does not have any influence on either the selection of funding priorities or the actual grant decision. Nevertheless, the boundaries between government and foundation grants can sometimes be blurry. In the U.S. context, for example, the National Science Foundation (NSF) and the National Institutes of Health (NIH) are both U.S. government agencies. However, both agencies are largely driven by "scientific opportunities" that are communicated through broad topic announcements and funding mechanisms that attract investigator initiated proposals. Peer review is the main funding mechanism for both NSF and $\mathrm{NIH}^{2}$

The fourth type of grants analysed in this paper are industry grants which have been shown to have increased significantly in importance (OECD, 2010). Despite their increasing importance for public science, the lion's share of industrial research is carried out by the firms themselves. Nevertheless, the interaction between industry and science has received great attention in the literature. Knowledge produced by academia is an important ingredient of economic growth and technological progress (Jaffe, 1989; Adams, 1990). Close links to academic research have further been shown to be beneficial for innovation performance of the individual firm (e.g. Cockburn and Henderson, 1998). Consequently, numerous efforts have been made in order to increase industry-science linkages, including $R \& D$ tax credits for industry funding of academic research (Bozeman and Gaughan, 2007) or research and technology partnerships (e.g. Audretsch et al., 2002; Link and Scott, 2005). Probably most important for establishing grants-related contacts between academia and industry has been a shift in the regulation of who owns the rights to intellectual property like patents that university professors have developed. In Germany, the so-called "professor's privilege" was lifted in 2002, assigning the rights to intellectual property to the scientist's employer. Other European countries adopted similar regulations but this trend was actually preceded by the enactment of the Bayh-Dole Act in the U.S. in 1980 (Mowery et al., 2001). Facilitating the

2 Sources: NIH and NSF websites (http://www.nsf.gov/about/how.jsp, http://www.nih.gov/about/). Date of visit: 24/08/2011. 
transfer of intellectual property rights, this regulation smoothed the way for universities to engage in grants-related research.

The four types of grants, however, do not contribute equally to scientists' overall projectbased funding. Table 1 gives an overview of their respective importance for the year 2006, which marks the final year of the FP6.

Table 1 about here

The funding amounts are differentiated between universities and PROs to illustrate the differences within German public science. The difference between the amount that university scientists and scientists at PROs received in 2006 reflects at least partly the fact that universities also employed significantly more scientific personnel than PROs (OECD, 2010). It turns out that foundation grants constitute the most important source of funding for university researchers but the least important for PRO researchers. ${ }^{3}$ Both university and PRO scientists acquire a significant amount of their project-based funds from industry, followed by government grants. The FP6 was relatively unimportant for university scientists but somewhat more important for PRO scientists. In this respect, the table points at the heterogeneity of public science in Germany in terms of the funding patterns. It also suggests that the institutional affiliation might be an important determinant for whether a grant is attained from a particular source.

Another characteristic of the funding pattern is that project-based research is concentrated on a few universities. From 2005 to 2007, more than 75 per cent of all grants from the German Research Foundation were awarded to only 30 out of 92 German universities (DFG, 2009a). This concentration pattern also holds true for funding obtained from the FP6 and the government. Interestingly, it is the same group of universities that obtains most of the projectbased funding, regardless of the specific source of funding. The following section will therefore discuss several factors that might have an impact on funding outcomes.

\section{Determinants of funding outcomes}

In order to demonstrate the legitimacy of the funding allocation, a key tenet of virtually all funding processes is that outcomes should be meritocratic. For example, competitive and merit-based selection procedures have been described as a cornerstone of the FP6, and the research conducted in the thematic areas has been evaluated as being of international standard (Rietschel, 2009). Principal investigators in FP6-funded projects have been found to excel over their peers in terms of publications and citation performance (Technopolis, 2008). Moreover, participation in the FP is regarded as a "seal of quality" in many countries and an

3 It has to be noted though that funding data for PRO scientists regarding foundations other than the German Research Foundation are not available. The total amount of project-based funding is therefore higher than stated here. 
indicator of the scientific quality of the projects and the scientists involved (Rietschel, 2009). Some institutions like the University of Copenhagen even offer additional research money conditional upon being granted an FP project.

The strong emphasis on quality is motivated by the premise that public funds should not be wasted on less promising projects and less qualified applicants. In this context, it has been frequently recognised that academic research can be characterised by a "winner takes all" reward system in which the first to contribute a discovery in a peer-reviewed domain receives indirect and direct rewards, including citations, prizes, research grants or endowed chairs (Dasgupta and David, 1994; Sorensen and Fleming, 2004; Mudambi and Swift, 2009). At the same time, competition for research funding has increased considerably over the past decades as most scientists are to an increasing extent dependent on the acquisition of external grants in order to conduct research (Viner et al., 2004). Although Viner et al. (2004) find that decisions by funding agencies cannot be fully explained by a scientist's reputation for excellence, scientists typically succeed in a competitive funding allocation process because of their past performance. In this respect, past performance may have an effect on current performance because of a "cumulative advantage". Such an advantage basically reflects both past recognition and the stock of past knowledge accumulated by the scientist (Defazio et al., 2009). In other words, past performance is associated with the level of reputation necessary to attract research funding and to clear the hurdle of peer-review.

Basically the same mechanism applies to industry grants. Academic reputation serves as a signal to potential commercialisation partners in industry (Murray, 2004). Grimpe and Fier (2010) show that higher scientific productivity, along with other quality indicators such as tenure, increase the likelihood that academics will transfer technology or applied research results to industry, co-author papers with industry personnel, or serve as formal paid consultants to industrial firms. Besides highly-ranked publications, industry is therefore presumably also interested in any patents scientists have generated. Patents may serve as a mechanism to appropriate the returns from inventive activity and thus open up commercialisation opportunities for firms. In fact, recent studies for the U.S. and Germany show that publications and university patenting are positively linked (e.g. Agrawal and Henderson, 2002; Stephan et al., 2006; Czarnitzki et al., 2009).

Although the quality of a scientist's research has been characterised as a main determinant of funding outcomes, personal, institutional and disciplinary characteristics have a role to play too. In this regard, the scientist's position at his or her institution might have an impact on whether the scientist considers applying for grants necessary. If the scientist is heading a research group there might be a higher need to obtain external funding in order to finance (junior) positions in the scientist's research group. Further, tenured academics are typically more experienced with grant applications, which might improve their chances of obtaining funding (Grimpe and Fier, 2010). Moreover, experience contributes to the cumulative advantage. Highly credentialed scientists are able to maintain or even increase their productivity over time because they receive recognition and resources (Allison and Stewart, 1974). The likelihood of being funded should therefore increase with age although this relationship might turn negative after a certain threshold when scientists approach the end of 
their career. Similarly, patterns of grant activity may vary according to the scientist's gender, particularly when it comes to industry support (e.g. Corley and Gaughan, 2005).

A major characteristic of the German science system is the existence of PROs, which conduct a substantial share of research alongside the universities. Most PROs belong to one of the four large German science organisations: the Fraunhofer Society, Max Planck Society, Helmholtz Association, and Leibniz Association. The Fraunhofer Society is one of Europe's largest application-oriented research organisations and is geared towards generating income through contract research. The society acquires grants and contracts from both public and private sector sponsors. With more than 80 research units, including 60 Fraunhofer institutes, at different locations in Germany, it employs more than 18,000 scientists and engineers. The research budget totals 1.66 billion Euro, of which 1.40 billion Euro are project based funding. ${ }^{4}$ The remaining share is contributed by the federal and state governments as institutional funding. The orientation towards applied research suggests that Fraunhofer scientists might be particularly likely to acquire industry and government funds but less likely to obtain funding from foundations, which have been described as focusing more on basic research.

The Max Planck Society describes itself as Germany's "most successful research organisation”. Seventeen Nobel laureates have emerged from the ranks of its scientists, and more than 13,000 publications appear each year in internationally renowned scientific journals. The 80 Max Planck institutes with more than 16,000 scientists and other employees carry out basic research in the natural sciences, life sciences, social sciences, and the humanities. Max Planck institutes focus on research fields that are considered to be innovative or that are particularly demanding in terms of time requirements. About 80 per cent of the total budget is institutional funding from the government; the remaining share is acquired through research grants. ${ }^{5}$ Again, both the orientation of research as well as the relative independence from project funding might suggest that Max Planck scientists tend to strive for grants from foundations rather than from industry or another source.

The Helmholtz Association comprises 17 research centres and 33,000 employees with a total budget of 3.3 billion Euro, which makes it Germany's largest scientific organisation. The research centres pursue long-term research goals in the fields of energy, earth and environment, health, key technologies, structure of matter, and aeronautics, space and transport. Centres are characterised by employing large-scale facilities and scientific infrastructure with the objective of combining theoretical basic research with technology development for innovative applications. About two thirds of the association's budget is institutional funding provided by the government while one third stems from research grants. ${ }^{6}$ Given the institutes' research orientation, all four types of grants could potentially be of interest to Helmholtz scientists. However, due to the large share of institutional funding, the

4 Data obtained from the society’s website (http://www.fraunhofer.de). Date of visit: 24/08/2011.

5 Data obtained from the society's website (http://www.mpg.de). Date of visit: 24/08/2011.

6 Data obtained from the association's website (http://www.helmholtz.de). Date of visit: 24/08/2011. 
pressure to obtain research grants might not be as high as for scientists at Fraunhofer institutes.

The Leibniz Association is made up of 87 institutes that conduct application-oriented basic research and provide scientific infrastructure. With 16,800 employees, the total annual budget amounts to almost 1.4 billion Euro. In contrast to the other institutes, Leibniz institutes are characterised by a high degree of heterogeneity in terms of subjects and disciplines. Moreover, almost all Leibniz institutes are scientifically and organisationally independent, which is in stark contrast to Fraunhofer or Max Planck institutes, both of which have a central head office. Like Helmholtz institutes, research in Leibniz institutes is aimed at bridging basic and applied research. Moreover, about two thirds of the total budget is institutional funding from the government while one third stems from research grants. Most institutes have strong ties with universities, which is also reflected in the fact that many directors and leading scientists hold joint appointments as professors at neighbouring universities. ${ }^{7}$ Again, as for Helmholtz institutes, all types of grants could potentially be relevant to scientists at Leibniz institutes but the funding structure also suggests that the institutes are not too dependent on acquiring research grants.

Further, it is essential to consider disciplinary effects on the funding outcome. Disciplinary field effects are widely acknowledged as important in a range of faculty activities (e.g. Edler et al., 2011). This is certainly also true when it comes to scientists' funding strategies. Several funding bodies employ thematic R\&D programmes that focus on certain fields of research. Scientists in those targeted fields will thus seek funding primarily from those sources. But there are also more subtle differences. Kotchen et al. (2004), for example, analyse the outcome of grant applications to the NIH that request support for clinical research. They find that grant outcomes are slightly less favourable for applications that involve clinical research than for those that involve laboratory research.

Finally, the factors determining the funding outcome might also be political, for example in terms of favouring a particular region in which an applicant is located. An evaluation study of FP6 commissioned by the German Federal Ministry of Education and Research finds that grantees from peripheral EU countries like Greece, Portugal or the Baltic states were able to acquire significantly more research funding per patent at the European Patent Office than large EU countries like Germany, France or the U.K. Moreover, smaller EU countries were typically more effective in acquiring EU funding in relation to what they spend on public research themselves (BMBF, 2009). These findings might serve as indications that political factors have an important role to play, too. However, as this paper is concerned with the German context only, political factors remain unconsidered in the analysis.

To sum up, although all funding agencies and industry claim to base their grant decisions on past performance, it might not only be the quality of the scientists' research that is decisive for the funding outcome. Other factors like personal, institutional and disciplinary characteristics might be relevant for explaining a scientist's choice of one source of grants over another.

Data obtained from the association's website (http://www.wgl.de). Date of visit: 24/08/2011. 
Following the basic logic outlined above, the other factors aside from research quality can be assumed to influence a scientist's funding strategy because they increase the probability of being awarded a grant (for example, because more grants are available in the scientist's field of research) and/or they lower the cost of applying and managing the project (for example, because PROs with a more centralised structure like Fraunhofer or Max Planck institutes dispose of central administrative support and know-how on how to apply compared to scientists at universities). The next section will thus analyse the determinants of funding outcomes while considering alternative funding schemes available in order to elucidate to what extent a scientist's research quality is decisive for the funding outcome compared to other factors.

\section{$4 \quad$ Empirical approach}

\subsection{Data}

The data used in the empirical analysis are derived from a survey among German scientists that was carried out within an evaluation project of the FP6 on behalf of the German Federal Ministry of Education and Research. The survey was designed to yield an overview of university scientists' efforts to acquire research funding from several different sources. Data collection took place in 2008 and was implemented using an online questionnaire. Contacting respondents via e-mail entails the risk of outdated or misspelled e-mail addresses. Nevertheless, online surveys serve as quick and efficient instruments to reach a large number of persons.

The sampling procedure involved two major data sources. First, German university professors and academic personnel with a PhD are listed in the "Hochschullehrerverzeichnis" with their names, degrees and contact information. ${ }^{8}$ As a substantial share of public science in Germany is performed in public research organisations, scientists at the four large German PROs - the Max Planck Society, the Fraunhofer Society, the Helmholtz Association and the Leibniz Association - holding a PhD were identified via an internet search of the institutes' websites. Combining these two data sources yielded 16,269 valid e-mail addresses. ${ }^{9}$ We obtained 2,797 responses, a response rate on the gross sample of 17.2 per cent. Comparable surveys of academics in Germany yield a very similar response rate (e.g. Edler et al., 2011). In a second step, data on publications of the scientists were collected through a manual search in the ISI Web of Science database. Findings were restricted to include only articles, letters, notes, proceedings papers, and reviews. Moreover, information on patent applications of the scientists was compiled from the PATSTAT worldwide patent statistical database which is

8 This excludes the so-called "universities of applied sciences”, whose major task is teaching and not research.

9 Only doctorate holders were targeted for this survey to make sure that respondents had some research (and possibly grant) experience. The gross sample size is therefore much smaller than the employee figures stated above might suggest. 
published by the European Patent Office. ${ }^{10}$ Not all scientists could be identified unambiguously in those two databases and were thus excluded. The omission of scientists with missing values in the variables of interest for this study results in a final sample of 855 observations. $^{11}$

To scrutinise the representativeness of the sample, data on the distribution of scientists across scientific disciplines in the population of German public research scientists were obtained from the Federal Statistical Office. Based on the classification used by the German Research Foundation, the full-time scientific personnel was grouped into four scientific fields: natural sciences (e.g. chemistry, physics, mathematics), engineering sciences (e.g. process, chemical, or construction engineering), life sciences (e.g. medicine, biology, plant sciences), and the social sciences and humanities. Table 2 shows the distribution of scientists in Germany and the realised sample. A distinction is drawn between scientists working at a university and those working at a PRO. The PROs focus largely on the natural sciences while research in the social sciences and humanities is predominantly carried out at universities. In order to compare the population with the realised sample, both groups need to be weighted and aggregated. It turns out that the sample contains slightly more scientists working in engineering and life sciences, 1.5 and 4.9 per cent more respectively. Scientists in the natural sciences and the social sciences and humanities are slightly under-represented, 3.6 and 3.8 per cent fewer respectively. Overall, these differences are not alarming. Acknowledging the potential biases induced by the different distribution of scientists across disciplines, the sample can thus be assumed to provide a reasonable representation of scientists in Germany. ${ }^{12}$

Table 2 about here

10 Data on patent families were retrieved. A patent family represents a single invention that could have led to patent applications at several patent offices. Although there may be differences in the technological and economic importance of patent applications, for example between the European Patent Office and national patent offices, this research primarily investigates whether scientists consider the commercialisation of their research results and not potential differences between the institutional loci of patent application.

11 There are basically three reasons that may explain the difference between the number of responses and observations used in this study: a) as commonly observed in online surveys, many potential respondents logged in (and thus are counted as "response"), but did not actually answer any questions or answered only a few; b) the survey was primarily used to analyse the participation of public scientists in the FP6 as it was commissioned by the German ministry of education and research. The first part of the survey was thus dedicated to FP6, and the broader questions, including those on other grants sought, were asked in the second part. As a result, many respondents did not complete all necessary modules under consideration here. Only about 1,400 scientists filled in the whole questionnaire; c) the remaining 1,400 observations had some item non-response which, after combining them with publication and patent data, led to the final sample of 855 scientists. Because this response pattern might raise concern about the representativeness of the results, the following comparison shows that the population of scientists is well-represented in relative terms when the sample is stratified for instance by fields of study.

12 In an ideal case, a non-response analysis would have used a control sample of non-respondents for whom information on gender, age, discipline and institution is available. Unfortunately, neither the register data nor the institutes' homepages reveal that information that would make it possible to perform such an analysis. 


\subsection{Measures}

The measures for the use of grants are based on faculty responses. Scientists were asked whether they had been awarded ${ }^{13}$ one of the four different types of research grants: the FP6, the German government, foundations, and industry. If so, they were asked to indicate the share that this particular grant contributed to their total budget that stems from grants. The time frame the scientists were asked to refer to was from 2002 to 2006, which corresponds to the duration of the FP6.

Our main explanatory variables reflect the individual scientist's research, personal and institutional characteristics as well as scientific discipline. Research characteristics are measured by the scientist's productivity, i.e. the stock of publications and patent (family) applications, both summed up until 2002 to avoid any influence that subsequent grants could have had on research productivity. As both the publication and patent stock are skewed, the variables enter the regression in logarithm (after adding 1 to avoid missing values for those scientists with no publications or patents at all). A third measure of research characteristics includes a dummy variable indicating whether a scientist is head of a research group. Personal characteristics are measured by whether the scientist is tenured (dummy), female (dummy) and by the scientist's age. Age is also included as a squared term to control for a non-linear relationship.

Institutional characteristics refer on the one hand to the size of the scientist's institution, measured as the number of colleagues who work in a similar field of research as indicated by the scientist. This variable is intended to capture the scientist's working environment and size of the peer group. Due to the skewness of the variable, it enters the regressions in logarithm (plus 1). On the other hand, universities have different institutional set-ups than PROs in Germany. The regressions thus include dummy variables for a scientist's affiliation with one of the four large science organisations (Fraunhofer Society, Max Planck Society, Helmholtz Association, Leibniz Association) and a dummy for any other institutional affiliation. University scientists are the largest group and are thus used as reference group. A small number of scientists is dually affiliated with both a university and a PRO. A separate dummy variable is thus introduced to control for such dual affiliation. Finally, the regressions control for the scientific field of the scientist (dummy variables for life sciences; chemistry, physics, mathematics, and computer sciences; engineering sciences; with social sciences and humanities being the reference category).

\subsection{Model}

The choice of the dependent variables is reflected by the estimation strategy. First, a multivariate probit model for the scientists' choice of the four different types of grants is estimated: the FP6, the German government, foundations, and industry. The multivariate probit model does not only explore the effects of the explanatory variables outlined above but also provides a test of the correlation of the error terms for the four types of grants conditional

13 This includes participation in a research consortium that jointly applied for a grant. 
on the vector of covariates (Athey and Stern, 1998; Cassiman and Veugelers, 2006). A positive and significant correlation coefficient $r$ ho between two grants suggests that these two grants are complementary, i.e. scientists make use of both funding sources to secure their budget. If the coefficient is negative, both grants can be regarded as substitutive, i.e. scientists tend to focus on either one of the grants. The relationship between the four types of grants and their simultaneity is further explored by estimating four probit models which include those three types of grant variables as additional regressors, which are not used as dependent variables. Second, tobit models for the share of funding that stems from one of the four funding sources are estimated.

In both the probit and the tobit model there is a potential selection effect in that a scientist who did not get funding through a particular funding scheme could either have not applied for the grant at all or have been unsuccessful with her or his application. Thus, ideally a selection model is required to estimate the likelihood of filing an application for a particular grant and to yield an efficient estimate for the likelihood of being funded through a particular grant. In the following, the models are estimated without such a selection step for two reasons. First, this research is interested in the outcome - which is the likelihood of obtaining funding from a specific source - and not in the determinants of filing an application. Second, and more importantly, while the FP6 was a single programme it featured a multitude of calls during the period from 2002 to 2006 for which scientists could apply. Moreover, there is a bewildering variety of grants and funding instruments available from the three other sources of financing. An appropriate selection model would thus need to consider potential applications to all the different calls and grants available from the four sources. Nevertheless, in order to increase confidence in the results, a robustness check is performed using additional information available from the questionnaire. Scientists were asked to indicate on a Likert scale from 1 (not important at all) to 5 (very important) how important the acquisition of extramural research grants is for a continuation of their research activities. If scientists face high pressure to acquire grants (indicated by a value of 4 or 5 on the Likert scale) it can be assumed that they actually had to file a grant application during the years 2002 to 2006 . Consequently, for the robustness check the sample is restricted to those scientists who indicate high pressure to acquire grants. The results will be described in the next section.

\section{$5 \quad$ Results}

\subsection{Descriptive statistics}

Table 3 shows the descriptive statistics of the dependent as well as our main explanatory and control variables.

Table 3 about here

The scientists in the sample have frequently received grants from the various sources. More than half of the scientists were involved in an FP6 sponsored research project, followed by 
grants from foundations, the government, and industry. On average, scientists received more than one third of their funds from foundations, followed by 25 per cent from the FP6, 20 per cent from the government, and 11 per cent from industry. This indicates that foundations are by far the most important source for financing. Only 15 scientists indicated that they had not been funded by any of the four types of grants.

Regarding the explanatory variables, scientists have on average a publication stock of 37 and a patent stock of 2.4. More than 75 per cent are heads of a research group and more than 82 per cent are tenured. There are 15 per cent female scientists in the sample and the average age is 49 years. The average size of each scientist's peer group is 24, indicating a rather large number of colleagues that the respondent indicates as working in her or his scientific field. Most respondents are university scientists, followed by scientists at one of the Helmholtz or Leibniz Association research centres, at the Max Planck Society and at the Fraunhofer Society. Four per cent of the scientists have a dual affiliation with both a university and a PRO. Finally, most scientists are in the life sciences, followed by chemistry, physics, mathematics and computer sciences, engineering sciences, and social sciences and humanities.

Table 4 shows pair wise correlations for the explanatory variables. As expected, it turns out that the measures for the scientist's research quality - particularly publications and patents are moderately correlated. Both variables also exhibit a positive correlation with the scientist's age. However, there is no indication of collinearity in the data as evidenced by an average variance inflation factor (VIF) of only 1.39 (Belsley et al., 1980).

Table 4 about here

\subsection{Multivariate analysis}

Table 5 presents the results from the multivariate probit models on having obtained a grant from the four different funding sources. Probit models are sensitive to the assumption of normality of the error distribution. Following Verbeek (2000: 187) a test statistic is calculated that is based on the Lagrange multiplier approach. The test statistic follows a Chi2 distribution with two degrees of freedom. It turns out that the assumption of normality cannot be rejected only for the probit model explaining the award of an FP6 grant. Thus, as a robustness check logit models are estimated which appear to be fully consistent with the probit results. As a consequence, only the results from the (multivariate) probit are reported. ${ }^{14}$

Table 5 about here

14 The results of the logit regressions are available from the author upon request. 
The results for the research characteristics variables show that the scientist's past productivity in terms of publication stock has a significant and positive effect only on the likelihood of obtaining funding from foundations. The coefficients are insignificant for all other types of grants. Patenting turns out to be positively related to foundation and industry grants. In this respect, the two main output indicators for a scientist's research activities appear to be irrelevant for obtaining grants from the FP6 or the government. Particularly for FP6 funding, this finding is in stark contrast to the initial assumption that the scientists attracted to the FP6 are among the most credentialed. With respect to industry funding, the findings are somewhat in contrast to prior research on star scientists' involvement in biotechnological research (Zucker and Darby, 1996; Zucker et al., 2002), which indicates that particularly high publication activities qualify scientists as attractive research partners for industry. A potential reason for publications being insignificant in predicting whether scientists will obtain an industry grant is that the sample is not restricted to life scientists but instead comprises all disciplines. Being the head of a research group has a significant and positive effect on the likelihood of obtaining a grant from all four sources. Apparently, these scientists have to support and finance a group of more junior researchers. They can also be assumed to be more experienced with grant applications. Hence, their propensity to take advantage of the various types of grants should be higher. Regarding the scientist's personal characteristics it turns out that being tenured only increases the likelihood of obtaining a government grant. Neither the scientist's gender nor age have any effect at all.

Considerable differences can be observed with respect to the institutional characteristics. The size of the scientist's peer group appears to be positively related to obtaining funding from the FP6, the government, and on a 10 per cent significance level also from foundations. Hence it seems that particularly FP6 and government grants are awarded to larger groups of researchers, which might be attributable to two reasons. On the one hand, it could suggest that the types of grants offered are more appropriate for larger groups because the application might require research consortia. On the other hand, it could also suggest that FP6 and government grants are awarded on the basis of the already existing research capacity of the applicant's institution, which the grants increase by even more. When focus is turned to scientists' affiliation with a particular type of PRO, some selective effects can be identified. Scientists at the Fraunhofer Society exhibit a significantly lower propensity to be funded by foundations compared to university scientists, who constitute the reference category. As Fraunhofer scientists' work is typically highly application-oriented, this negative effect does not come as a surprise. Positive effects can instead be found for government and industry funding as all Fraunhofer institutes maintain close contacts with industry. In contrast to this, the need of scientists at the Max Planck Society's institutes to acquire external grants is limited. This is substantiated by negative and significant coefficients for government and industry grants. Scientists at Helmholtz institutes exhibit a higher likelihood to be funded by FP6 grants compared to university researchers. They have, however, a lower likelihood of receiving grants from foundations and industry. Finally, scientists at Leibniz institutes are more likely to be funded by government grants compared to university scientists.

With respect to the scientist's discipline, it turns out that working in the life sciences, chemistry/physics/mathematics, and engineering sciences increases the chances of receiving 
funding from the FP6 in comparison to the social sciences and humanities. This finding substantiates the fact that the FP6 held few opportunities for scientists in these disciplines. Engineering scientists also have higher chances of receiving funding from government and industry. There is however a negative effect of engineering sciences on the probability of receiving a grant from foundations. Social sciences and humanities as the reference category thus seem to be more prominent in these grant programmes.

Additionally, the multivariate probit model makes it possible to test for correlation of the error terms rho between the four equations. It turns out that there is no significant correlation of the FP6 equation's error term with the one of the government equation. There is a negative correlation with the error terms in the foundation and industry equations. Moreover, the results show significant rhos for the government grant equation and the foundation and industry grant equations. Rho is negative for foundation grants and positive for industry grants. Finally, rho is insignificant for the foundation and industry grant equations. To further explore these relationships, Table 6 shows the results of four probit models, each of which includes the three other grant dummy variables not used as dependent variables. It turns out that all results are robust. In other words, the FP6 is not found to be complementary to any of the other grant programmes but instead substitutive. Government grants are substitutive to foundation and complementary to industry grants. This finding suggests that scientists in Germany will typically not attempt to build a portfolio of different grants but instead focus on a certain type of grant. It implies that scientists specialise considerably and that they target those funding sources from which they expect the most success on the basis of their research, individual and institutional characteristics because these either increase the probability of attaining the grant or lower the cost of applying for it.

Table 6 about here

Table 7 reports the results of the tobit models for the share of the scientist's budget stemming from one of the four grants. Most of the results found in the multivariate probit model can be confirmed although less significant coefficients are observed. As in the probit case, publication productivity is a statistically significant determinant of the funding share from foundations while patenting activity is a statistically significant determinant of the funding share from industry. Both measures turn out to be irrelevant for FP6 and government funding. Moreover, being the head of a research group only influences the funding share that comes from government grants. In contrast to the probit model, the results show that being a female scientist reduces the funding share that stems from industry. The effect of the scientist's peer group size is significant and positive only for the share of funding from FP6 and government grants.

The findings for the remaining institutional and disciplinary variables turn out to be as in the probit case. Fraunhofer scientists raise a higher share of their budget from government grants or industry and a lower share from foundations. This finding confirms the effects of these scientists' application-oriented research activities. Max Planck scientists have fewer incentives to acquire research grants as evidenced by the insignificant or negative coefficients. 
The FP6 seems to be a predominant source of funding for scientists from the Helmholtz institutes. They also finance their activities to a lesser extent through foundation grants. Scientists at Leibniz institutes receive a higher share of their funding from government grants but also a lower share from foundation grants. Regarding the scientific disciplines, it turns out that scientists from all disciplines except the social sciences and humanities use FP6 grants to finance their budget, confirming the results of the multivariate probit model. Moreover, as expected, engineers raise a lower share from foundations but are significantly more engaged with the government and industry.

Table 7 about here

As outlined above, robustness checks of the results are performed using information on whether scientists perceive high pressure to acquire extramural research grants to continue their research activities. It turns out that this holds true for 88 per cent of the scientists in the sample. The results confirm the findings of the main models. ${ }^{15}$

\section{Discussion and conclusions}

This paper explores the funding strategies of public sector scientists and draws a distinction between four major groups of grants. The analysis yields several interesting results that provide insights for public policy and the scientists involved in grant application processes. First and foremost, the results show that the claim that virtually all funding processes are meritocratic and based on past scientific achievements needs qualification. Both major indicators of a scientist's research quality, publications and patents, fail to significantly determine whether an FP6 or a government grant is awarded. Both publications and patents turn out to be important for achieving a foundation grant while patents predict industry grants. This result is striking because particularly participation in an FP6 grant has been widely regarded as a "quality seal" for the researchers involved (Rietschel, 2009). Another result of an evaluation study is that FP6 projects involved the contribution of excellent scientists, measured in terms of publications and received citations (Technopolis, 2008). While these findings are undisputed, this study is the first to contrast participation in the FP6 with other funding opportunities available to scientists. Based on research quality in terms of publications and patents generated by the scientists, this study suggests that the FP6 actually did not succeed in attracting the scientific “A Team” (Rietschel, 2009). Instead, publications and patents turn out to be particularly important for attaining foundation and industry grants. If it is true, as the findings here suggest, that not all funding processes are strictly meritocratic, it raises concerns as to whether FP6 and government grants in particular are suitable to increase the efficiency and productivity of public research because it might not necessarily be the best ideas and most capable scientists that win the grants.

15 The result tables are available from the author upon request. 
The results of this study further suggest that other factors have an important role to play in determining the funding outcome. While personal characteristics turn out to be largely insignificant, it is especially the fact of whether a scientist heads a research group as well as institutional and disciplinary characteristics that determine the funding outcome. The former finding has implications for the incentive effects in R\&D teams. Mudambi et al. (2007), for example, study the consequences of intrinsic motivators on global innovation and find that productivity of a research team decreases if credit is disproportionately assigned to the head of the research group rather than being shared amongst team members. In this regard, the findings of this paper can be interpreted as partly off-setting the negative "team work effect" with a positive "funding effect" because having the head of the research group on the application significantly increases the probability of obtaining the grant.

The findings for the institutional characteristics indicate strong preferences of scientists from science organisations for a particular grant. The effects observed are mostly as expected from the description of the organisations. Fraunhofer scientists' work is strongly application oriented and they therefore have success primarily with industry and government grants. Max Planck scientists apparently have little pressure to acquire research grants. Helmholtz scientists have a higher likelihood of being involved in FP6 grants while Leibniz scientists are more involved in government grants. As one of the main motivations of the FPs has been to build capacity, it is not surprising that scientists at large Helmholtz institutes are particularly likely to be involved in FP6 grants. This finding is substantiated when the size of the scientist's peer group is taken into account. Larger group size is in fact a statistically significant determinant only for FP6 and government grants.

More surprising and insightful are the findings on the relationships between the four types of grants. There are indications of complementarity for government and industry grants only while all other grants can be considered as substitutes. This finding suggests that scientists specialise considerably in certain types of grants and that being able to acquire one particular grant does not necessarily mean that the scientist is better able to acquire other types of grants. This substantiates the conclusion that funding outcomes reflect meritocracy to a surprisingly limited extent and it suggests that particularly FP6 grants can be considered as more "political" than the other types of grants. In this respect, the FP6 provided funding to very different scientists who rarely make use of other funding instruments. Given that this research relies on a cross-section, little can be said, however, to what extent high-prestige grants may serve as certification in applications for subsequent grants.

The policy lesson from this research is not unambiguous. On the one hand, the European Commission has left no doubt that the FPs are intended to complement national research funding by a supra-national instrument that seeks to facilitate collaboration among excellent scientists across Europe in order to create an integrated European Research Area supporting innovation, economic growth and prosperity. If we accept this policy rationale then there is a considerable need for adjusting the FP towards becoming more meritocratic. In fact, most funding instruments within the FP have frequently been criticised for being too inflexible and pre-determined with respect to a number of features, including, for example, the size and the structure of the consortia, the thematic orientation, the application procedure, or the 
requirements for project management (e.g. Rietschel, 2009). Similar adjustments are likely to be also warranted in the case of government grants.

On the other hand, this research has demonstrated that there seems to be a functional "division of labour" between the FP, government, foundation and industry grants, which cater to different profiles of scientists. As the research orientation differs among the population of scientists, it seems problematic to cut back on those grants that support more application or consulting oriented research that does not necessarily lead to publications or patents. The Fraunhofer society, for example, demonstrates that success in terms of support delivered to the German innovation system through consulting and contract research is not exclusively tied to higher publication or patent output. As a result, changing the programmes so that they become more meritocratic might actually bring about negative effects for the innovation system as a whole. Although academic research has been described as a driver of innovative activity in firms and economic growth (e.g. Jaffe, 1989), it is also oftentimes more distant from actual application (Siegel et al., 2004). In this regard, academic research requires higher absorptive capacity of firms to be actually of use in innovation processes (Cohen and Levinthal, 1990; Fabrizio, 2009). Providing funding for activities that facilitate the transfer of knowledge and technology from academia to industry thus seems essential. However, a change in some of the current policy rhetoric to reflect to a greater extent the actual award criteria is warranted.

This research is not free from limitations. First, the grants were grouped under four rather broad headings, which might not adequately reflect the heterogeneity of grants and funding bodies. However, the four types group together grants that are sufficiently similar and recognisable by the scientists. Second, due to the variety of grants over the period from 2002 to 2006 it was not possible to disentangle the determinants of applying for a particular grant at all and the determinants of the funding outcome. Future research should thus try to obtain more fine-grained data in order to evaluate the importance of research quality versus other factors as determinants of an application and the actual funding outcome. Moreover, it would be interesting to analyse the persistence of funding choices over time, which would require longitudinal data. At the same time, however, award criteria could change, which would create additional challenges. 


\section{References}

Adams, J.D. (1990), Fundamental Stocks of Knowledge and Productivity Growth, Journal of Political Economy 98, 673-702.

Adams, J.D. (2005), Scientific Teams and Institutional Collaborations: Evidence from U.S. Universities, 1981-1999, Research Policy 34, 259-285.

Agrawal, A. and R. Henderson (2002), Putting Patents in Context: Exploring Knowledge Transfer from MIT, Management Science 48 (1), 44-60.

Allison, P.D. and J.A. Stewart (1974), Productivity Differences among Scientists: Evidence for Accumulative Advantage, American Sociological Review 39, 596-606.

Arora, A., P.A. David and A. Gambardella (1998), Reputation and Competence in Publicly Funded Science: Estimating the Effects on Research Group Productivity, Annales d'Economie et de Statistique 49/50, 163-198.

Arora, A. and A. Gambardella (2006), The Impact of NSF Support on Basic Research in Economics, Les Annales d'Economie et des Statistiques forthcoming.

Athey, S. and S. Stern (1998), An Empirical Framework for Testing Theories About Complementarity in Organizational Design, NBER Working Paper No. 6600, Boston.

Audretsch, D.B., A.N. Link and J.T. Scott (2002), Public/Private Technology Partnerships: Evaluating SBIR-Supported Research, Research Policy 31, 145-158.

Auranen, O. and M. Nieminen (2010), University Research Funding and Publication Performance - an International Comparison, Resarch Policy 39, 822-834.

Belsley, D.A., E. Kuh and R.E. Welsh (1980), Regression Diagnostics: Identifying Influential Data and Sources of Collinearity, New York.

BMBF (2008), Bundesbericht Forschung und Innovation 2008, Berlin.

BMBF ed. (2009), Studie zur Deutschen Beteiligung am 6. Forschungsrahmenprogramm der Europäischen Union, Bonn/Berlin.

Bolli, T. and F. Somogyi (2011), Do Competitively Acquired Funds Induce Universities to Increase Productivity?, Resarch Policy 40, 136-147.

Bozeman, B. and M. Gaughan (2007), Impacts of Grants and Contracts on Academic Researchers’ Interactions with Industry, Research Policy 36, 694-707.

Cassiman, B. and R. Veugelers (2006), In Search of Complementarity in the Innovation Strategy: Internal R\&D and External Knowledge Acquisition, Management Science 52 (1), 68-82.

Cockburn, I.M. and R.M. Henderson (1998), Absorptive Capacity, Coauthoring Behavior, and the Organization of Research in Drug Discovery, Journal of Industrial Economics 46 (2), 157-182.

Cohen, W.M. and D.A. Levinthal (1990), Absorptive Capacity: A New Perspective on Learning and Innovation, Administrative Science Quarterly 35 (1), 128-152.

Corley, E. and M. Gaughan (2005), Scientists' Participation in University Research Centers: What Are the Gender Differences, Journal of Technology Transfer 30, 371-381.

Czarnitzki, D., W. Glänzel and K. Hussinger (2009), Heterogeneity of Patenting Activity and Its Implications for Scientific Research, Research Policy 38, 26-34.

Dasgupta, P. and P. David (1994), Towards a New Economics of Science, Research Policy 3, 487-521.

Defazio, D., A. Lockett and M. Wright (2009), Funding Incentives, Collaborative Dynamics and Scientific Productivity: Evidence from the Eu Framework Program, Research Policy 38, 293-305.

DFG (2009a), Förder-Ranking 2009, Weinheim. 
DFG (2009b), Leibniz Prize 2010: Ten Winners Receive Honour, Prize Money and "Idyllic Freedom",

http://www.dfg.de/en/service/press/press_releases/2009/pressemitteilung_nr_65/index. html.

Edler, J., H. Fier and C. Grimpe (2011), International Scientist Mobility and the Locus of Knowledge and Technology Transfer, Resarch Policy 40, 791-805.

European Commission (2002), The 6th Framework Programme in Brief, Brussels.

Fabrizio, K.R. (2009), Absorptive Capacity and the Search for Innovation, Research Policy 38, 255-267.

Godin, B. (2003), The Impact of Research Grants on the Productivity and Quality of Scientific Research, INRS Working Paper No. 2003, Ottawa.

Grimpe, C. and H. Fier (2010), Informal University Technology Transfer: A Comparison between the United States and Germany, Journal of Technology Transfer 35, 637-650.

Jaffe, A. (1989), Real Effects of Academic Research, American Economic Review 97 (5), 957-970.

Kotchen, T.A., T. Lindquist, K. Malik and E. Ehrenfeld (2004), NIH Peer Review of Grant Applications for Clinical Research, Journal of the American Medical Association 291 (7), 836-843.

Lee, S. and B. Bozeman (2005), The Impact of Research Collaboration on Scientific Productivity, Social Studies of Science 35, 673-702.

Link, A.N. and J.T. Scott (2005), Universities as Partners in U.S. Research Joint Ventures, Research Policy 34, 385-393.

Luukkonen, T. (2002), Technology and Market Orientation in Company Participation in the EU Framework Programme, Research Policy 31, 437-455.

Marin, P.L. and G. Siotis (2008), Public Policies Towards Research Joint Venture: Institutional Design and Participants' Characteristics, Research Policy 37, 1057-1065.

Mowery, D.C., R.R. Nelson, B.N. Sampat and A.A. Ziedonis (2001), The Growth of Patenting and Licensing by U.S. Universities: An Assessment of the Effects of the Bayh-Dole Act of 1980, Research Policy 30 (1), 99-119.

Mudambi, R., S.M. Mudambi and P. Navarra (2007), Global Innovation in MNCs: The Effects of Subsidiary Self-Determination and Teamwork, Journal of Product Innovation Management 24, 442-455.

Mudambi, R. and T. Swift (2009), Professional Guilds, Tension and Knowledge Management, Research Policy 38, 736-745.

Murray, F. (2004), The Role of Academic Inventors in Entrepreneurial Firms: Sharing the Laboratory Life, Research Policy 33, 643-659.

OECD (2010), Main Science and Technology Indicators, Paris.

Rietschel, E.T. (2009), Evaluation of the Sixth Framework Programmes for Research and Technological Development 2002-2006, Brussels.

Schmoch, U. and T. Schubert (2009), Sustainability of Incentives for Excellent Research - the German Case, Scientometrics 81 (1), 195-218.

Siegel, D.S., D.A. Waldman, L.E. Atwater and A.N. Link (2004), Toward a Model of the Effective Transfer of Scientific Knowledge from Academicians to Practitioners: Qualitative Evidence from the Commercialization of University Technologies, Journal of Engineering and Technology Management 21, 115-142.

Sorensen, O. and F. Fleming (2004), Science and the Diffusion of Knowledge, Research Policy 33, 1615-1633.

Stephan, P.E. (1996), The Economics of Science, Journal of Economic Literature 34, 11991235.

Stephan, P.E., S. Gurmu, A.J. Sumell and G. Black (2006), Who's Patenting in the University?, Economics of Innovation and New Technology 16 (2), 71-99. 
Technopolis (2008), Bibliometric Profiling of FP6 Participants, London.

Verbeek, M. (2000), A Guide to Modern Econometrics, Hoboken, NJ.

Viner, N., P. Powell and R. Green (2004), Institutionalized Biases in the Award of Research Grants: A Preliminary Analysis Revisiting the Principle of Accumulative Advantage, Research Policy 33, 443-454.

Zucker, L.G. and M.R. Darby (1996), Star Scientists and Institutional Transformation: Patterns of Invention and Innovation in the Formation of the Biotechnology Industry, Proceedings of the National Academy of Sciences No., Irvine, CA.

Zucker, L.G., M.R. Darby and J.S. Armstrong (2002), Commercializing Knowledge: University Science, Knowledge Capture, and Firm Performance in Biotechnology, Management Science 48 (1), 138-153. 


\section{Tables}

Table 1: Funding amounts by source (2006)

\begin{tabular}{lrrrrr}
\hline & FP6 & Government & Foundations & Industry & Total \\
\hline University & $€ 369,984$ & $€ 747,676$ & $€ 1,456,812$ & $€ 1,345,076$ & $€ 3,919,548$ \\
scientists & $9.4 \%$ & $19.1 \%$ & $37.2 \%$ & $34.3 \%$ & $100.0 \%$ \\
& & & & & \\
PRO scientists & $€ 293,366$ & $€ 441,467$ & $€ 231,600 *$ & $€ 852,000$ & $€ 1,818,433$ \\
& $16.1 \%$ & $24.3 \%$ & $12.7 \%$ & $46.9 \%$ & $100.0 \%$ \\
\hline
\end{tabular}

Amounts are in thousands of Euro.

Source: OECD, 2010; DFG (German Research Foundation), 2009; Federal Statistical Office, 2007.

* Only contains funding from DFG, other sources unavailable.

Table 2: Distribution of scientists across disciplines in Germany (2005)

\begin{tabular}{lcccc}
\hline & $\begin{array}{c}\text { Share } \\
\text { university } \\
\text { scientists }\end{array}$ & $\begin{array}{c}\text { Share PRO } \\
\text { scientists }\end{array}$ & $\begin{array}{c}\text { Share } \\
\text { total } \\
\text { scientists }\end{array}$ & Realised sample \\
\hline Natural sciences & $24.0 \%$ & $46.2 \%$ & $31.1 \%$ & $28.5 \%$ \\
Engineering sciences & $15.8 \%$ & $26.3 \%$ & $19.3 \%$ & $20.8 \%$ \\
Life sciences & $30.4 \%$ & $14.3 \%$ & $25.2 \%$ & $30.1 \%$ \\
Social sciences and humanities & $29.8 \%$ & $13.2 \%$ & $24.4 \%$ & $20.6 \%$ \\
Total & $100.0 \%$ & $100.0 \%$ & $100.0 \%$ & $100.0 \%$ \\
\hline Source: Federal Statistical Office, 2011; author's calculations. & \multicolumn{3}{l}{} \\
\hline
\end{tabular}


Table 3: Descriptive statistics

\begin{tabular}{|c|c|c|c|c|c|}
\hline Variable & Obs. & Mean & Std. Dev. & Min. & Max. \\
\hline \multicolumn{6}{|l|}{ Dependent variables } \\
\hline Grant from FP6 (d) & 855 & 0.602 & 0.490 & 0 & 1 \\
\hline Grant from government (d) & 855 & 0.519 & 0.500 & 0 & 1 \\
\hline Grant from foundations (d) & 855 & 0.674 & 0.469 & 0 & 1 \\
\hline Grant from industry (d) & 855 & 0.393 & 0.489 & 0 & 1 \\
\hline Budget share from FP6 & 855 & 0.245 & 0.301 & 0 & 1 \\
\hline Budget share from government & 855 & 0.201 & 0.266 & 0 & 1 \\
\hline Budget share from foundations & 855 & 0.349 & 0.361 & 0 & 1 \\
\hline Budget share from industry & 855 & 0.111 & 0.212 & 0 & 1 \\
\hline \multicolumn{6}{|l|}{ Explanatory variables } \\
\hline \multicolumn{6}{|l|}{ Research characteristics } \\
\hline No. of publications (stock) & 855 & 37.566 & 61.563 & 0 & 460 \\
\hline No. of patent applications (stock) & 855 & 2.425 & 8.414 & 0 & 103 \\
\hline Head of research group (d) & 855 & 0.759 & 0.428 & 0 & 1 \\
\hline \multicolumn{6}{|l|}{ Personal characteristics } \\
\hline Tenured (d) & 855 & 0.827 & 0.379 & 0 & 1 \\
\hline Gender (d, 1 = female) & 855 & 0.150 & 0.357 & 0 & 1 \\
\hline Age (years) & 855 & 49.504 & 8.144 & 30 & 74 \\
\hline \multicolumn{6}{|l|}{ Institutional characteristics } \\
\hline Size of peer group & 855 & 24.432 & 57.420 & 0 & 500 \\
\hline University (d) & 855 & 0.651 & 0.477 & 0 & 1 \\
\hline Fraunhofer Society (d) & 855 & 0.055 & 0.228 & 0 & 1 \\
\hline Max Planck Society (d) & 855 & 0.067 & 0.250 & 0 & 1 \\
\hline Helmholtz Association (d) & 855 & 0.150 & 0.357 & 0 & 1 \\
\hline Leibniz Association (d) & 855 & 0.068 & 0.252 & 0 & 1 \\
\hline Other institution (d) & 855 & 0.053 & 0.223 & 0 & 1 \\
\hline Dual affiliation (d) & 855 & 0.041 & 0.198 & 0 & 1 \\
\hline \multicolumn{6}{|l|}{ Scientific disciplines } \\
\hline Social sciences and humanities (d) & 855 & 0.206 & 0.405 & 0 & 1 \\
\hline Life sciences (d) & 855 & 0.301 & 0.459 & 0 & 1 \\
\hline Chemistry, physics, mathematics (d) & 855 & 0.285 & 0.452 & 0 & 1 \\
\hline Engineering sciences (d) & 855 & 0.208 & 0.406 & 0 & 1 \\
\hline
\end{tabular}




\section{Table 4: Correlation table}

\begin{tabular}{|c|c|c|c|c|c|c|c|c|c|c|c|c|c|c|c|c|}
\hline & 1. & 2. & 3. & 4. & 5. & 6. & 7. & 8. & 9. & 10. & 11. & 12. & 13. & 14. & 15. & 16. \\
\hline 1. No. of publications (stock, log) & 1.00 & & & & & & & & & & & & & & & \\
\hline 2. No. of patent applications (stock, log) & 0.19 & 1.00 & & & & & & & & & & & & & & \\
\hline 3. Head of research group $(d)$ & 0.13 & 0.09 & 1.00 & & & & & & & & & & & & & \\
\hline 4. Tenured (d) & 0.17 & 0.11 & 0.15 & 1.00 & & & & & & & & & & & & \\
\hline 5. Gender (d, 1 = female) & -0.14 & -0.13 & -0.07 & -0.13 & 1.00 & & & & & & & & & & & \\
\hline 6. Age (years) & 0.17 & 0.15 & 0.06 & 0.30 & -0.12 & 1.00 & & & & & & & & & & \\
\hline 7. Size of peer group (log) & 0.16 & 0.06 & 0.05 & 0.00 & -0.10 & -0.06 & 1.00 & & & & & & & & & \\
\hline 8. Fraunhofer Society (d) & -0.06 & 0.16 & -0.04 & 0.02 & -0.01 & -0.07 & 0.15 & 1.00 & & & & & & & & \\
\hline 9. Max Planck Society (d) & 0.09 & 0.01 & -0.06 & -0.15 & -0.01 & -0.05 & 0.10 & -0.06 & 1.00 & & & & & & & \\
\hline 10. Helmholtz Association (d) & 0.08 & -0.02 & -0.16 & 0.01 & 0.02 & -0.07 & 0.28 & -0.10 & -0.11 & 1.00 & & & & & & \\
\hline 11. Leibniz Association (d) & -0.07 & -0.01 & -0.10 & 0.00 & 0.00 & -0.02 & 0.01 & -0.07 & -0.07 & -0.11 & 1.00 & & & & & \\
\hline 12. Other institution (d) & -0.06 & 0.01 & -0.03 & -0.03 & 0.05 & 0.04 & 0.03 & -0.06 & -0.04 & -0.08 & -0.06 & 1.00 & & & & \\
\hline 13. Dual affiliation (d) & -0.01 & -0.01 & -0.01 & -0.09 & -0.00 & -0.09 & 0.04 & 0.08 & 0.06 & 0.11 & 0.09 & 0.14 & 1.00 & & & \\
\hline 14. Life sciences (d) & 0.30 & 0.00 & 0.09 & -0.04 & 0.07 & -0.02 & 0.09 & -0.09 & 0.08 & -0.03 & 0.03 & 0.04 & 0.04 & 1.00 & & \\
\hline 15. Chemistry, physics, mathematics (d) & 0.13 & -0.04 & -0.04 & 0.04 & -0.07 & -0.03 & 0.05 & -0.04 & 0.09 & 0.21 & 0.04 & -0.03 & -0.03 & -0.41 & 1.00 & \\
\hline 16. Engineering sciences (d) & -0.05 & 0.16 & 0.03 & 0.10 & -0.13 & 0.02 & 0.05 & 0.24 & -0.13 & 0.01 & -0.08 & 0.01 & 0.01 & -0.34 & -0.32 & 1.00 \\
\hline
\end{tabular}

(d): dummy variable 
Table 5: Multivariate probit model for the determinants of funding outcomes

\begin{tabular}{|c|c|c|c|c|}
\hline & \multicolumn{4}{|c|}{ Research grant received from } \\
\hline & FP6 & government & foundations & industry \\
\hline \multirow[t]{2}{*}{ No. of publications (stock, log) } & 0.010 & 0.018 & $0.120 * * *$ & 0.051 \\
\hline & $(0.033)$ & $(0.033)$ & $(0.035)$ & $(0.035)$ \\
\hline \multirow[t]{2}{*}{ No. of patent applications (stock, log) } & 0.026 & 0.047 & $0.135^{* *}$ & $0.183 * * *$ \\
\hline & $(0.054)$ & $(0.053)$ & $(0.060)$ & $(0.053)$ \\
\hline \multirow[t]{2}{*}{ Head of research group (d) } & $0.225^{* *}$ & $0.354^{* * *}$ & 0.189 & $0.309 * *$ \\
\hline & $(0.114)$ & $(0.111)$ & $(0.117)$ & $(0.124)$ \\
\hline \multirow[t]{2}{*}{ Tenured (d) } & 0.144 & $0.261^{*}$ & 0.025 & 0.066 \\
\hline & $(0.140)$ & $(0.139)$ & $(0.146)$ & $(0.151)$ \\
\hline \multirow[t]{2}{*}{ Gender (d, 1 = female) } & 0.111 & -0.112 & 0.176 & -0.190 \\
\hline & $(0.132)$ & $(0.130)$ & $(0.139)$ & $(0.146)$ \\
\hline \multirow[t]{2}{*}{ Age (years) } & -0.099 & 0.044 & -0.021 & -0.012 \\
\hline & $(0.063)$ & $(0.064)$ & $(0.064)$ & $(0.066)$ \\
\hline \multirow[t]{2}{*}{ Age (years) ${ }^{2}$} & 0.001 & 0.000 & 0.000 & 0.000 \\
\hline & $(0.001)$ & $(0.001)$ & $(0.001)$ & $(0.001)$ \\
\hline \multirow[t]{2}{*}{ Size of peer group (log) } & $0.148^{* * *}$ & $0.109 * * *$ & $0.087^{*}$ & 0.048 \\
\hline & $(0.043)$ & $(0.041)$ & $(0.044)$ & $(0.043)$ \\
\hline \multirow[t]{2}{*}{ Fraunhofer Society (d) } & -0.015 & $0.863 * * *$ & $-0.916 * * *$ & $1.653 * * *$ \\
\hline & $(0.241)$ & $(0.265)$ & $(0.227)$ & $(0.343)$ \\
\hline \multirow{2}{*}{ Max Planck Society (d) } & -0.225 & $-0.562 * * *$ & -0.015 & $-0.459 * *$ \\
\hline & $(0.186)$ & $(0.203)$ & $(0.218)$ & $(0.210)$ \\
\hline \multirow[t]{2}{*}{ Helmholtz Association (d) } & $0.368 * *$ & $-0.245^{*}$ & $-0.799 * * *$ & $-0.336^{* *}$ \\
\hline & $(0.161)$ & $(0.144)$ & $(0.153)$ & $(0.163)$ \\
\hline \multirow{2}{*}{ Leibniz Association (d) } & 0.193 & $0.444^{* *}$ & -0.227 & -0.182 \\
\hline & $(0.186)$ & $(0.187)$ & $(0.195)$ & $(0.200)$ \\
\hline \multirow[t]{2}{*}{ Other institution (d) } & $0.400^{*}$ & 0.204 & $-1.360 * * *$ & -0.096 \\
\hline & $(0.209)$ & $(0.206)$ & $(0.215)$ & $(0.230)$ \\
\hline \multirow{2}{*}{ Dual affiliation (d) } & 0.007 & 0.344 & $0.565^{* *}$ & -0.220 \\
\hline & $(0.253)$ & $(0.241)$ & $(0.266)$ & $(0.272)$ \\
\hline \multirow[t]{2}{*}{ Life sciences (d) } & $0.326^{* *}$ & 0.220 & -0.033 & 0.120 \\
\hline & $(0.148)$ & $(0.149)$ & $(0.160)$ & $(0.156)$ \\
\hline \multirow[t]{2}{*}{ Chemistry, physics, mathematics (d) } & $0.522 * * *$ & $0.245^{*}$ & -0.070 & -0.059 \\
\hline & $(0.148)$ & $(0.147)$ & $(0.154)$ & $(0.160)$ \\
\hline \multirow[t]{2}{*}{ Engineering sciences (d) } & $1.127 * * *$ & $0.536 * * *$ & $-0.666 * * *$ & $1.026 * * *$ \\
\hline & $(0.160)$ & $(0.153)$ & $(0.159)$ & $(0.165)$ \\
\hline \multirow[t]{2}{*}{ Constant } & 1.815 & -1.940 & 0.502 & -0.906 \\
\hline & $(1.543)$ & $(1.584)$ & $(1.568)$ & $(1.636)$ \\
\hline \multirow{3}{*}{$\begin{array}{l}\text { rho (FP6 and (2), (3), (4)) } \\
\text { rho (government and (3), (4)) } \\
\text { rho (foundations and (4)) }\end{array}$} & & 0.035 & $-0.105 *$ & $-0.172 * * *$ \\
\hline & & & $-0.187 * * *$ & $0.202 * * *$ \\
\hline & rho (foundations and (4)) & & & -0.010 \\
\hline $\mathrm{N}$ & 855 & & & \\
\hline Wald Chi2 & 530.39 & & & \\
\hline P-value & 0.000 & & & \\
\hline \multicolumn{5}{|c|}{$\begin{array}{l}\text { (d): dummy variable; standard errors in parentheses. } \\
*, * *, * * * \text { indicate statistical significance at the } 10 \%, 5 \% \text { and } 1 \% \text { level } \\
\text { Reference categories: university affiliation; social sciences and humanities }\end{array}$} \\
\hline
\end{tabular}


Table 6: Probit models for the determinants of funding outcomes

\begin{tabular}{|c|c|c|c|c|}
\hline & \multicolumn{4}{|c|}{ Research grant received from } \\
\hline & FP6 & government & foundations & industry \\
\hline \multirow[t]{2}{*}{ No. of publications (stock, log) } & 0.026 & 0.021 & $0.124 * * *$ & 0.051 \\
\hline & $(0.033)$ & $(0.033)$ & $(0.035)$ & $(0.036)$ \\
\hline \multirow[t]{2}{*}{ No. of patent applications (stock, log) } & 0.051 & 0.032 & $0.142 * *$ & $0.190 * * *$ \\
\hline & $(0.055)$ & $(0.054)$ & $(0.061)$ & $(0.054)$ \\
\hline \multirow[t]{2}{*}{ Head of research group (d) } & $0.269 * *$ & $0.336 * * *$ & $0.248 * *$ & $0.291 * *$ \\
\hline & $(0.116)$ & $(0.114)$ & $(0.120)$ & $(0.128)$ \\
\hline \multirow[t]{2}{*}{ Tenured (d) } & 0.149 & $0.254^{*}$ & 0.068 & 0.034 \\
\hline & $(0.139)$ & $(0.139)$ & $(0.145)$ & $(0.151)$ \\
\hline \multirow[t]{2}{*}{ Gender (d, 1 = female) } & 0.122 & -0.078 & 0.185 & -0.155 \\
\hline & $(0.132)$ & $(0.132)$ & $(0.140)$ & $(0.148)$ \\
\hline \multirow[t]{2}{*}{ Age (years) } & $-0.106^{*}$ & 0.050 & -0.028 & -0.030 \\
\hline & $(0.063)$ & $(0.065)$ & $(0.064)$ & $(0.067)$ \\
\hline \multirow[t]{2}{*}{ Age (years) ${ }^{2}$} & 0.001 & -0.001 & 0.000 & 0.000 \\
\hline & $(0.001)$ & $(0.001)$ & $(0.001)$ & $(0.001)$ \\
\hline \multirow[t]{2}{*}{ Size of peer group (log) } & $0.162 * * *$ & $0.109 * * *$ & $0.118^{* * *}$ & 0.042 \\
\hline & $(0.044)$ & $(0.042)$ & $(0.045)$ & $(0.043)$ \\
\hline \multirow[t]{2}{*}{ Fraunhofer Society (d) } & -0.053 & $0.631 * *$ & $-0.874 * * *$ & $1.546^{* * *}$ \\
\hline & $(0.251)$ & $(0.268)$ & $(0.229)$ & $(0.346)$ \\
\hline \multirow[t]{2}{*}{ Max Planck Society (d) } & -0.260 & $-0.498 * *$ & -0.126 & $-0.413^{*}$ \\
\hline & $(0.189)$ & $(0.201)$ & $(0.219)$ & $(0.215)$ \\
\hline \multirow[t]{2}{*}{ Helmholtz Association (d) } & 0.253 & $-0.280 *$ & $-0.809 * * *$ & $-0.287^{*}$ \\
\hline & $(0.166)$ & $(0.151)$ & $(0.156)$ & $(0.167)$ \\
\hline \multirow[t]{2}{*}{ Leibniz Association (d) } & 0.134 & $0.462 * *$ & -0.178 & -0.237 \\
\hline & $(0.189)$ & $(0.191)$ & $(0.197)$ & $(0.202)$ \\
\hline \multirow[t]{2}{*}{ Other institution (d) } & 0.231 & 0.096 & $-1.322 * * *$ & -0.121 \\
\hline & $(0.215)$ & $(0.215)$ & $(0.218)$ & $(0.237)$ \\
\hline \multirow[t]{2}{*}{ Dual affiliation (d) } & 0.052 & $0.404^{*}$ & $0.588 * *$ & -0.243 \\
\hline & $(0.260)$ & $(0.244)$ & $(0.265)$ & $(0.281)$ \\
\hline \multirow[t]{2}{*}{ Life sciences (d) } & $0.341 * *$ & 0.189 & 0.052 & 0.125 \\
\hline & $(0.149)$ & $(0.149)$ & $(0.161)$ & $(0.157)$ \\
\hline \multirow[t]{2}{*}{ Chemistry, physics, mathematics (d) } & $0.518^{* * *}$ & 0.233 & 0.031 & -0.042 \\
\hline & $(0.149)$ & $(0.148)$ & $(0.155)$ & $(0.165)$ \\
\hline \multirow[t]{2}{*}{ Engineering sciences (d) } & $1.154^{* * *}$ & $0.293^{*}$ & $-0.471 * * *$ & $1.065 * * *$ \\
\hline & $(0.166)$ & $(0.167)$ & $(0.171)$ & $(0.172)$ \\
\hline \multirow[t]{2}{*}{ Grant received from FP6 (d) } & & 0.073 & $-0.332 * * *$ & $-0.251 * *$ \\
\hline & & $(0.100)$ & $(0.105)$ & $(0.104)$ \\
\hline \multirow[t]{2}{*}{ Grant received from government (d) } & 0.062 & & $-0.272 * * *$ & $0.410 * * *$ \\
\hline & $(0.099)$ & & $(0.104)$ & $(0.099)$ \\
\hline \multirow[t]{2}{*}{ Grant received from foundations (d) } & $-0.358 * * *$ & $-0.273^{* *}$ & & -0.050 \\
\hline & $(0.108)$ & $(0.107)$ & & $(0.115)$ \\
\hline Grant received from industry (d) & $-0.255^{* *}$ & $0.435^{* * *}$ & -0.032 & \\
\hline & $(0.106)$ & $(0.102)$ & $(0.115)$ & \\
\hline Constant & 2.175 & -2.046 & 0.803 & -0.443 \\
\hline & $(1.557)$ & $(1.599)$ & $(1.574)$ & $(1.664)$ \\
\hline $\mathrm{R} 2$ & 0.126 & 0.110 & 0.154 & 0.203 \\
\hline $\mathrm{N}$ & 855 & 855 & 855 & 855 \\
\hline Wald Chi2 & 116.677 & 110.774 & 146.63 & 176.312 \\
\hline P-value & 0.000 & 0.000 & 0.000 & 0.000 \\
\hline $\begin{array}{l}\text { (d): dummy variable; standard errors in } \\
*, * *, * * * \text { indicate statistical significanc } \\
\text { Reference categories: university affilia }\end{array}$ & $\begin{array}{l}\text { entheses. } \\
\text { he } 10 \%, 5 \% \\
\text { social scien }\end{array}$ & $\begin{array}{l}\text { d } 1 \% \text { level } \\
\text { and humanitie }\end{array}$ & & \\
\hline
\end{tabular}


